\title{
Impacts of genomics on the health and social costs of intellectual disability
}

\author{
Brett Doble $(0), 1,2$ Deborah Schofield, ${ }^{1,3}$ Carey-Anne Evans, ${ }^{4}$ Tudor Groza, ${ }^{5}$ \\ John S Mattick, ${ }^{1,6}$ Mike Field, ${ }^{7}$ Tony Roscioli ${ }^{4,8}$
}

- Additional material is published online only. To view, please visit the journal online (http://dx.doi.org/10.1136/ jmedgenet-2019-106445).

${ }^{1}$ Garvan Institute of Medical Research, Darlinghurst, New South Wales, Australia

${ }^{2}$ Programme in Health Services and Systems Research, Duke-

NUS Medical School, Singapore, Singapore

${ }^{3}$ Genlmpact, School of Economics, Faculty of Business and Economics, Macquarie University, Sydney, New South Wales, Australia

${ }^{4}$ Neuroscience Research Australia, Prince of Wales Clinical School, University of New South Wales, Randwick, New South Wales, Australia ${ }^{5}$ Pryzm Health, Gold Coast, Queensland, Australia ${ }^{6}$ St Vincent's Clinical School, University of New South Wales, Sydney, New South Wales, Australia

${ }^{7}$ The Genetics of Learning Disability Service, Waratah, New South Wales, Australia ${ }^{8}$ NSW Health Pathology East Laboratory, Prince of Wales Private Hospital, Randwick, New South Wales, Australia

Correspondence to Dr Brett Doble, Garvan Institute of Medical Research, Darlinghurst, NSW 2010. Australia;

brett.doble@duke-nus.edu.sg

Received 16 July 2019 Revised 17 December 2019 Accepted 3 January 2020 Published Online First 24 January 2020

\section{Check for updates}

(c) Author(s) (or their employer(s)) 2020. No commercial re-use. See rights and permissions. Published by BMJ.

To cite: Doble B, Schofield D, Evans C-A, et al. J Med Genet 2020:57:479-486.

\section{ABSTRACT}

Background This study provides an integrated assessment of the economic and social impacts of genomic sequencing for the detection of monogenic disorders resulting in intellectual disability (ID).

Methods Multiple knowledge bases were crossreferenced and analysed to compile a reference list of monogenic disorders associated with ID. Multiple literature searches were used to quantify the health and social costs for the care of people with ID. Health and social expenditures and the current cost of wholeexome sequencing and whole-genome sequencing were quantified in relation to the more common causes of ID and their impact on lifespan.

Results On average, individuals with ID incur annual costs in terms of health costs, disability support, lost income and other social costs of US\$172000, accumulating to many millions of dollars over a lifetime. Conclusion The diagnosis of monogenic disorders through genomic testing provides the opportunity to improve the diagnosis and management, and to reduce the costs of ID through informed reproductive decisions, reductions in unproductive diagnostic tests and increasingly targeted therapies.

\section{INTRODUCTION}

Intellectual disability (ID) may be non-syndromic or syndromic, with various other body systems affected. Syndromic forms of ID may include those associated with epilepsy, inborn errors of metabolism and malformations of the central nervous system or other organs. Additional inherited conditions, such as cardiac and gastrointestinal syndromes associated with ID, may also occur, which in total result in almost 2000 disorders associated with ID. Highpenetrance, single-gene disorders, many of which are not inherited and occur de novo, ${ }^{1}$ account for approximately $20 \%$ of infant mortality ${ }^{2}$ and $10 \%$ of paediatric hospitalisations, ${ }^{3}$ with significant costs to the healthcare system and to families. Many children with a genetic disorder remain undiagnosed, ${ }^{4}$ leading to poorly optimised management, recurrence estimates limited to empiric risks and a failure to address psychosocial morbidity. ${ }^{5}$ Expensive and unproductive diagnostic odysseys have occurred frequently in the pregenomic era as a result of pursuing serial single-gene tests and invasive investigations, resulting in a low diagnostic yield for ID of $\sim 20 \% .^{67}$ Genomic testing has radically altered the rate of molecular diagnosis in individuals with monogenic disorders to approximately 50\%. ${ }^{18-10}$
Along with the decreasing cost of sequencing, these improvements have facilitated the transition of genomic testing from a research endeavour to clinical diagnosis. There is limited economic evidence supporting this transition. ${ }^{6}$ 11-16 The available studies that attempt to determine the cost-effectiveness of genomic testing ${ }^{121718}$ do not employ standard methods for the economic evaluation of health technologies, ${ }^{19}$ relying on simplified assumptions to estimate cost-effectiveness, largely due to lack of data to populate the models. ${ }^{2021}$

We have focused specifically on monogenic forms of ID, which are common and often also associated with physical disability. Four knowledge bases, Deciphering Developmental Disorders (DDD) UK (https://decipher.sanger.ac.uk/genes), PubMed (https://www.ncbi.nlm.nih.gov/pubmed/), Online Mendelian Inheritance in Man (OMIM) (https://www.omim.org) and Orphanet (https:// www.orpha.net/consor/cgi-bin/index.php), were cross-referenced and analysed to compile a reference list of monogenic disorders associated with ID. The health and social expenditures as a result of both ID and physical disability were also estimated and contrasted with the current costs of genomic testing. The results provide the first integrated assessment of the potential economic impacts of genomic testing for ID and offer a foundation for additional economic evaluations of the comprehensive detection of monogenic disorders that result in significant disability.

\section{MATERIALS AND METHODS Information sources and search}

The DDD UK, OMIM, ${ }^{22}$ PubMed and Orphanet knowledge bases were integrated and crossreferenced to compile a comprehensive list of monogenic diseases associated with ID (online supplementary figure S1). Additional PubMed literature searches were carried out by clinical geneticists and senior scientists (TR, MF and C-AE) on genes and disorders that were present in two or fewer databases to assess that they were in fact ID-confirmed genes by confirming that likely pathogenic or pathogenic variants had been identified in more than one unrelated individual and in more than one family. Genes and disorders not fulfilling these criteria were excluded from online supplementary table S1. While this study summarises the top 100 genes as determined by the numbers of pathogenic alleles reported in DDD UK, there are approximately 2000 genes recognised where ID is part of 
the phenotype, all with significant impacts on morbidity and mortality.

\section{Data items and synthesis of results}

Diseases identified were categorised based on affected body system with data items extracted, when available, from the databases for each individual gene and associated syndromes. The choice of body system in syndromic ID was based on whether a predominant organ system was involved. Items included disease reference information (OMIM reference), the associated gene, the body system affected, and items that may influence the economic and social benefits of determining the genetic aetiology, such as inheritance pattern and impact of disease on longevity (coded as $1=$ less than 2 years of life, $2=$ death by adolescence and $3=$ adult life expectancy).

\section{Cost analysis}

Studies reporting the healthcare and social costs related to either ID or physical disability were identified in two additional literature searches. The literature searches were targeted, in that initial searches were conducted in PubMed and then modified for Google Scholar searches and included search terms from three different categories: genetic disease nomenclature, economic terminology and social impacts. Citations of any studies assessed as important by the authors were also reviewed in Google Scholar to broaden the search space. The objective was to integrate the available data to determine reliable estimates of the annual costs of caring for people with disability, and therefore, any study reporting healthcare and/or social costs related to ID and/or physical disability in a patient population diagnosed with a monogenic condition were included. Information from related conditions with similar levels of disability (such as autism spectrum disorder and cerebral palsy) was added to those where specific costings related to disability were not available or limited. Some assumptions were made when synthesising the extracted data from the identified studies. First, where data were available, costs specific to four age groups (children $0-17$ years, young adults $18-29$ years, adults 30-60 years and older adults $>60$ years) were identified. This was to ensure that health and social expenditures could be estimated over the entirety of an affected individuals lifespan (ie, majority of the common causes of ID are associated with a lifespan reaching adulthood). Further subdivisions in childhood costs based on age, and in adult costs based on employment status, were also synthesised due to the potential for variations in expenditures throughout childhood and adulthood, respectively.

Costs were further grouped based on the severity of the condition (mild, moderate and severe). Note that it was not always possible to ascertain the approach used by authors to classify patients as mild, moderate and severe, and therefore, classification into these groups across studies may not be consistent. For the purposes of our study, the groupings were largely based on the reporting of the terms mild, moderate and severe, rather than formal diagnostic criteria. Hence, there was a need to account for this uncertainty. Therefore, lower, middle and upper boundary estimates were determined for each subgroup when summing the costs to account for uncertainty. A pragmatic approach to estimating the lower, middle and upper bounds was taken, given the fact that more than three studies may have been available for a particular group and/or type of cost. In the most straightforward case (three studies available), the lower and upper boundary estimates were the minimum and maximum costs identified for that subgroup. In cases where four or more studies were identified, additional syntheses were required, which usually involved averaging identified estimates to obtain low, middle and upper estimates. A mean value was then calculated from the lower, middle and upper boundary estimates and presented with its associated range. When only one data source and SD was available, the mean was used as the middle boundary with plus and minus the SD to determine the upper and lower (fixed at 0 in cases of negative numbers) boundaries, respectively. Where only one data source was available and there was no measure of variance, the same estimate was used across all three boundaries. To account for the variability in use of certain high-cost services (such as accommodation), costs were adjusted based on the proportion of individuals reported to receive those services. For example, the accommodation costs for adults reported by Knapp et $a^{23}$ were estimated across four subgroups: (1) adults living in a private household, (2) adults living in supported accommodation, (3) adults living in residential care and (4) adults living in a hospital. Reported proportions of adults with ID in Australia living under each of these four categories ${ }^{24}$ were therefore applied to the respective costs before totalling the costs to obtain the upper boundary estimate of accommodation costs for adults as well as elderly adults with ID. All costs were annualised (multiplied by 52 or 12 when initially reported as weekly or monthly costs, respectively), inflated and converted to 2018 US dollars using an appropriate component of a country-specific Consumer Price Index ${ }^{25}$ or Wage Price Index, ${ }^{26-29}$ depending on the country perspective taken in the original costing study, and rounded off in the text to two significant figures. All healthcare costs, accommodation costs, education costs and daytime activities were inflated to 2018 prices using country-specific Organisation for Economic Co-Operation and Development (OECD) all items non-food, non-energy Consumer Price Indexes. Income support and loss of productivity costs were inflated to 2018 prices using the public and private all industries Australian Wage Price Index (December 2018) for costs originally reported in Australian dollars $^{26}$ or a ratio of average annual nominal earnings for the years of interest for costs originally reported in British pound sterling, ${ }^{27}$ or a ratio of the average hourly nominal production workers compensation for the years of interest for costs originally reported in US dollars, ${ }^{28}$ or a ratio of the gross average monthly wages for the costs originally reported in Euros. ${ }^{29}$ Carer costs (composed of informal care, external care and out-of-pocket costs) were inflated to 2018 prices using the public and private all industries Australian Wage Price Index (December 2018) for costs originally reported in Australian dollars ${ }^{26}$ or a ratio of average annual nominal earnings for the years of interest for costs originally reported in British pound sterling, ${ }^{27}$ or a ratio of the average hourly nominal production workers compensation for the years of interest for costs originally reported in US dollars, ${ }^{28}$ or a ratio of the gross average monthly wages for the costs originally reported in Euros, ${ }^{29}$ or using country-specific OECD all items non-food, non-energy Consumer Price Indexes ${ }^{25}$ (out-of-pocket costs). All data used in the costing analysis and methods used to calculate the low, middle and upper estimates are provided in online supplementary excel file 1 .

Disability costs were separated into healthcare and social costs for intellectual and physical disability. Healthcare costs included hospital services, community services and treatment/aids/adaptations costs. Social costs included accommodation, education, daytime activities, income support (benefit payments, disability 
support services and employment support), carer costs (informal care, external care, out-of-pocket and travel costs) and loss of productivity (carer and individual).

\section{RESULTS}

\section{Identifiable monogenic disorders associated with disability}

The most frequent aetiologies for ID detectable through clinical genomic sequencing are presented in online supplementary table S1.

\section{The costs of ID}

Eighteen costing studies of ID were identified that reported either healthcare or social costs for at least one of the subgroups of interest. ${ }^{23} 2430-45$ A synthesis of these costs is detailed in table 1 , and the respective references used in each calculation are provided in online supplementary table S2.

Total healthcare costs associated with ID increased with age and severity of the disability until individuals reached adulthood. Healthcare costs were relatively smaller for children between the ages of 0 and 3 years regardless of the severity of the disability (range \$10000-\$19000) and were largest for children with a severe disability between the ages of 12 and 17 years (range \$17000-\$37000).

It has been underappreciated that the total costs of ID are driven substantially by social costs and that these are considerably larger than the associated healthcare costs. Total social costs associated with ID also increased with age and the severity of the disability until individuals reached young adulthood (ages 18-29 years), with one exception. Paradoxically, total costs for children $0-3$ years were larger for those with moderate ID (\$69000) compared with those with severe ID (\$64000). This is largely driven by lower income support and higher informal care costs for children with moderate ID and may be the result of those with severe ID being more able to access external formal care services, thus reducing demand for informal family-based care. As children reached the ages of 4-11 years, the social costs increase substantially (\$62 000-\$246000) largely due to the cost of special education and carer costs, and increase with severity of disability. Social costs for young adults are the largest compared with the other age groups, primarily due to the accommodation costs, and increase with disability severity (\$144 000-\$294 000).

Total costs increased by severity of ID and age, although costs were a little lower for older adults than those in young adulthood (\$37 000-\$90 000 for children age 0-3, \$152 000-329000 for young adults and $\$ 108000-\$ 252000$ for elderly adults).

\section{The costs of physical disability}

Of the 18 studies reporting the costs of ID, only $6^{363940424345}$ specifically provided details of whether or not the patient population assessed also suffered from physical disability. When specified, however, physical disability usually only affected a small proportion of the sample in addition to ID, making it difficult to ascertain what costs where attributable to only ID or only physically disability. Therefore, nine costing studies for the care of people with physical disability were identified that reported either healthcare or social costs for at least one of the age ranges, levels of severity and/or employment status. ${ }^{46-54}$ Note that only two studies ${ }^{4950}$ indicated that a small proportion of their patient samples may also have some form of mild ID. A synthesis of the costs reported in these studies is detailed in table 2 and the respective references used in each calculation are also provided in online supplementary table S3.
Total healthcare costs related to physical disability were greatest for children with severe physical disability, ranging from $\$ 647000$ to $\$ 961000$ (hospital-based care) and from $\$ 31000$ to $\$ 69000$ (home-based care). Healthcare costs for the young adult and adult groups were considerably lower compared with the two child groups, ranging from $\$ 1400$ to $\$ 5600$ and from $\$ 8400$ to $\$ 11000$, respectively.

Total social costs associated with physical disability were greatest in childhood as a result of relatively large benefit payments, travel costs, external care costs and carer loss of productivity. Unemployed young adults had very similar but slightly larger total social costs (range \$34000-\$101000) compared with unemployed adults (range \$34 000-\$97 000) due to the assumption that young adults incur some education costs in addition to daytime activity costs. Differences in total social costs between employed and unemployed young adults/adults were largely driven by the inclusion of carer loss of productivity only for employed individuals compared with the inclusion of both carer and individual loss of productivity for unemployed individuals.

The total costs of physical disability are the largest for children with a severe disability between the ages 0 and 17 years, ranging from $\$ 80000$ to $\$ 1.1$ million. These very high total costs are the result of the extreme severity of disability in the child population (ventilator-dependent children) from the main study used in our analysis. These total costs may therefore only be incurred by a small proportion of children with disabilities. However, even if a small number of children incur these costs, the magnitude of the costs in treating and supporting these children will have substantial impacts on total expenditure for all children with a disability.

\section{DISCUSSION}

The overall economic cost of caring for people with ID is extremely high, for families, health systems and society. These costs average $\$ 172000$ per person per year and have been significantly underestimated. Similar to a 'submerged iceberg', the healthcare costs associated with ID are largely apparent to both healthcare providers and decision makers, but much greater hidden social costs remain unappreciated. Compared with existing studies that have estimated the costs associated with ID, ${ }^{313341}$ our estimates are comprehensive and therefore much larger. Our estimates include all relevant costs incurred both within the healthcare system and broader society, whereas other studies have limited their assessments to only certain types of social costs ${ }^{33}$ or largely focused on healthcare costs and only a few types of social costs, with limited consideration of the full spectrum of costs affecting broader society. ${ }^{31} 41$

Currently, genomic testing in people with Mendelian disorders relies largely on whole-exome sequencing (WES) as a firstpass investigative methodology. WES trios including unaffected parents and an affected child are now routinely sequenced to increase test efficiency and utility as a significant proportion of people with ID have a de novo disease aetiology. ${ }^{55}$ The sequencing costs associated with WES have now fallen and are reported to be at least US\$500 per person. ${ }^{20}$ The costs of whole-genome sequencing (WGS) are higher but have fallen markedly in recent years and are reported to be at least US $\$ 1700$ per person for DNA sequencing. ${ }^{20}$ Incorporating the cost of variant interpretation increases costs by $\sim$ US $\$ 450^{56}$ plus the costs of computing infrastructure and data storage ( US\$100 per genome). ${ }^{57}$ Data analysis and interpretation costs are, however, decreasing for both WES and WGS as genotype-phenotype correlation databases $^{58}$ are populated and converted into automated queries. 


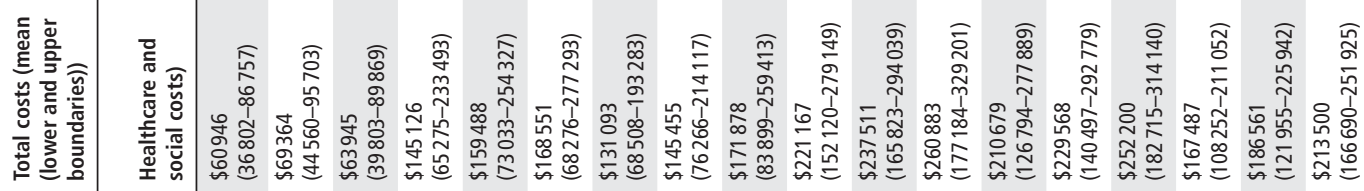

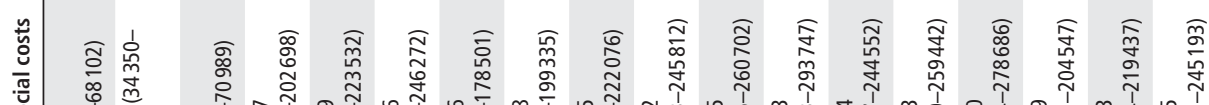

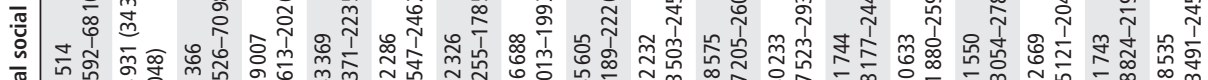

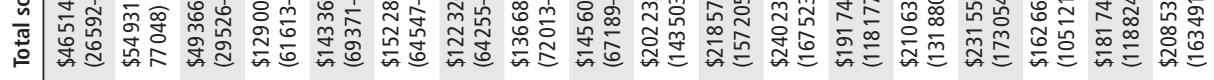

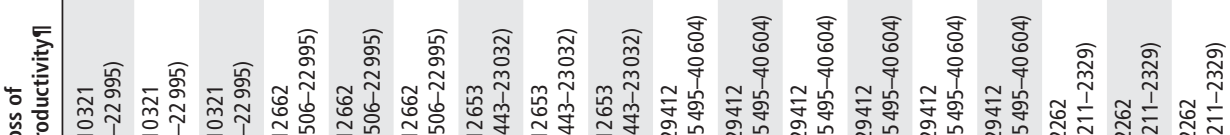

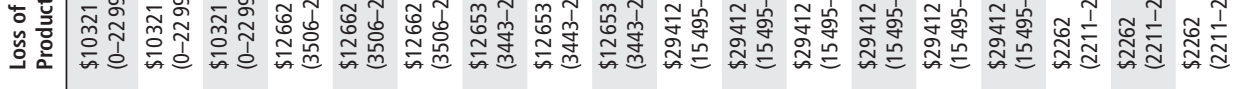

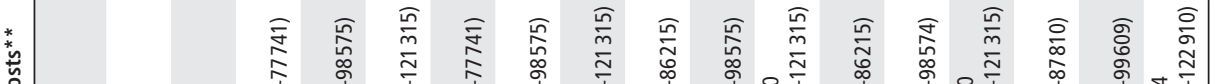

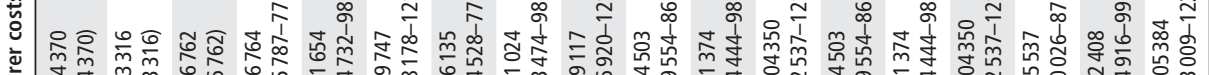

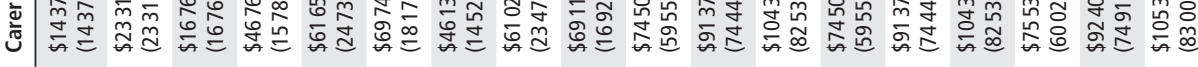

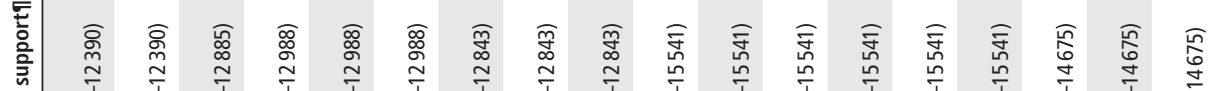

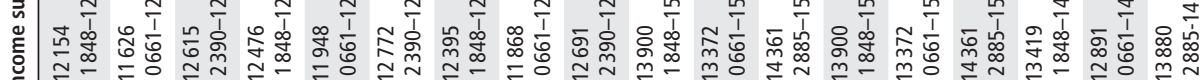

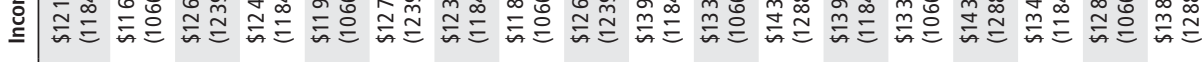

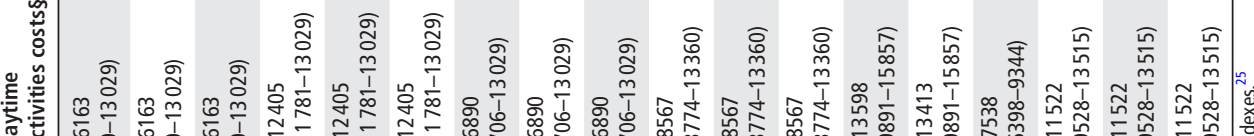

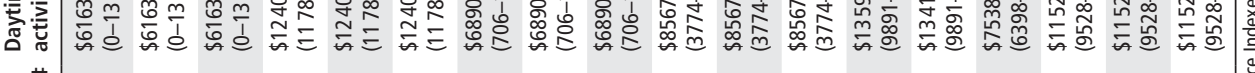

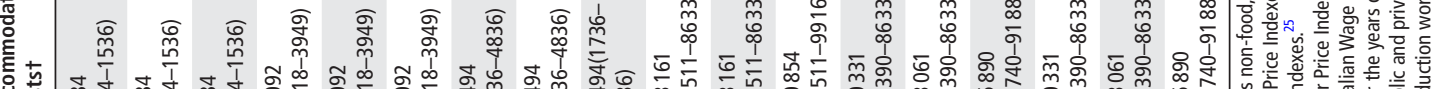

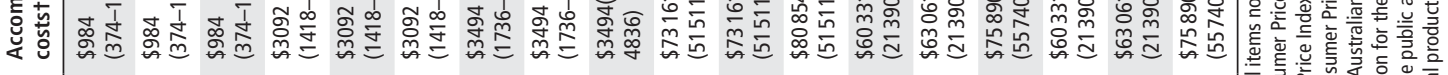

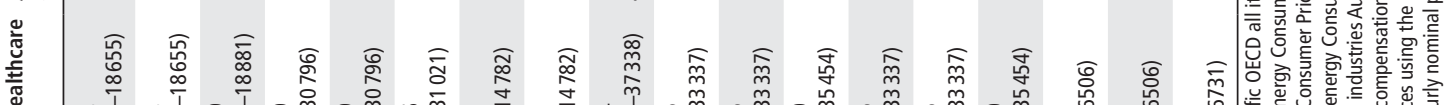

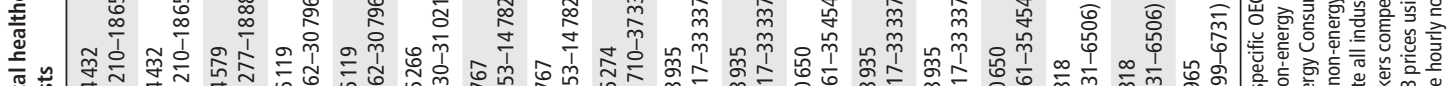

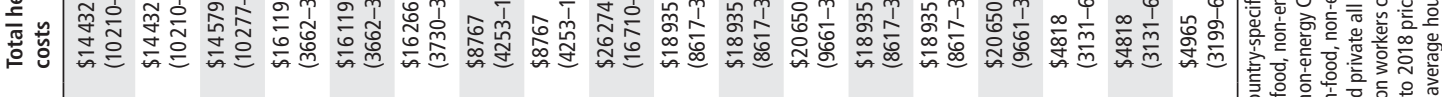

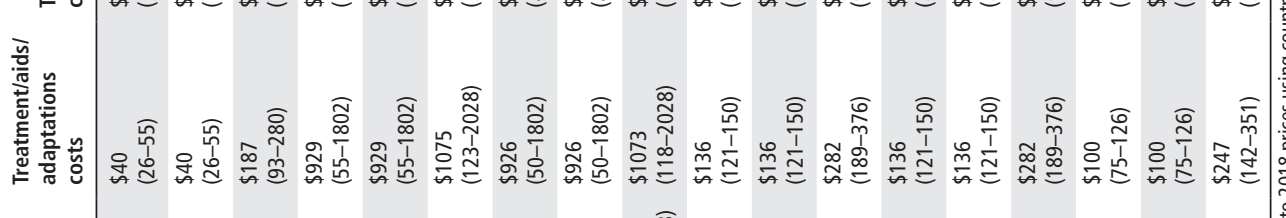

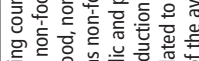

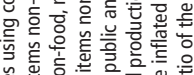

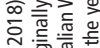

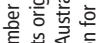

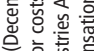

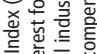

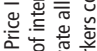

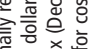

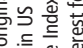

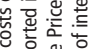

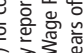
我

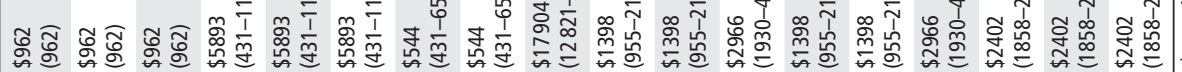

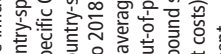

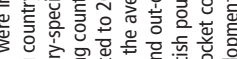

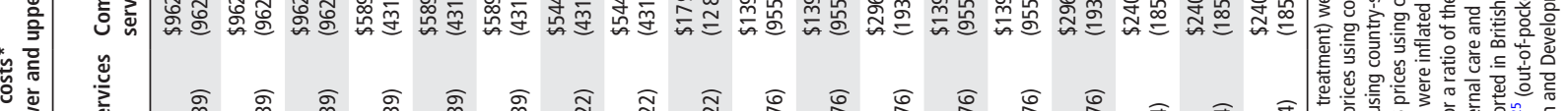

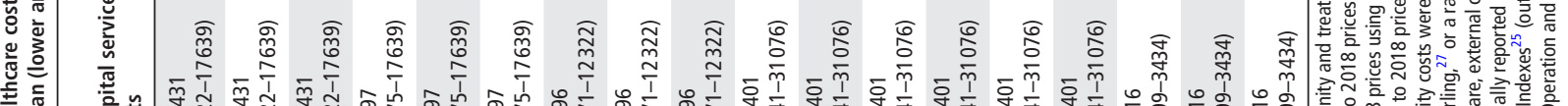

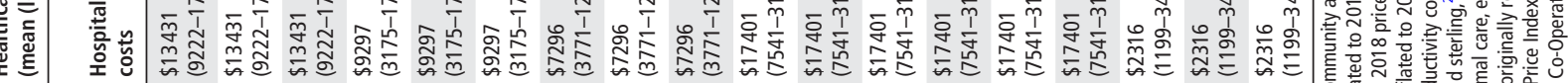
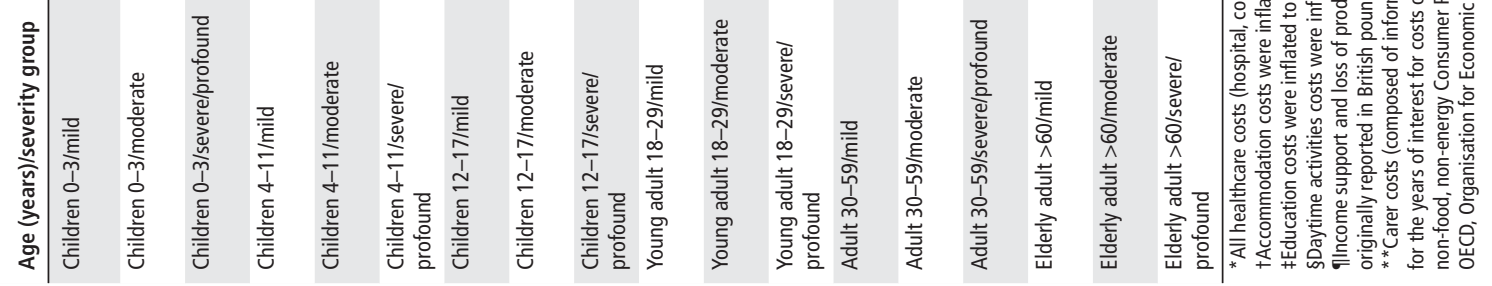


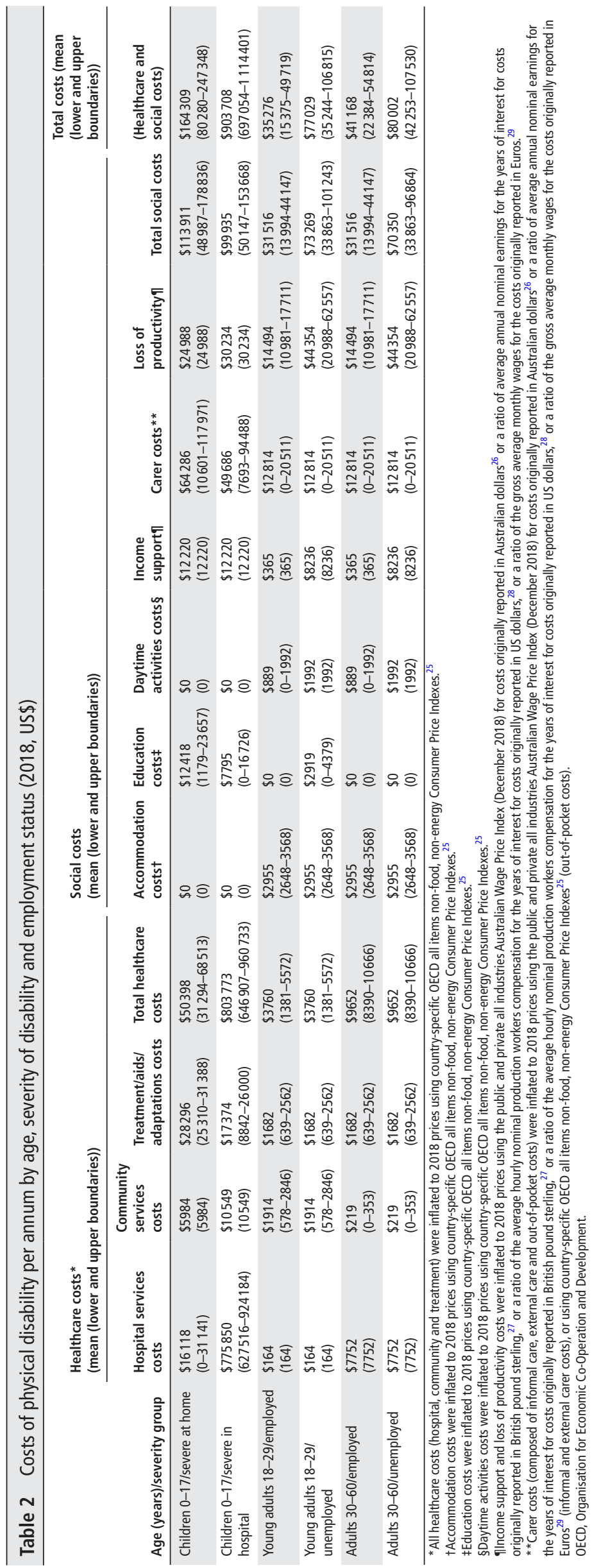


Costs associated with clinical follow-up appointments, investigations and referrals also increase overall costs associated with genomic sequencing. These additional costs have been estimated to be approximately US\$1000 per patient. ${ }^{59}$

Genomic testing may identify additional aetiologies in $\sim 50 \%$ of patients undiagnosed by chromosome microarray. ${ }^{8}$ WGS achieves a higher diagnostic rate for genetic disorders than WES ${ }^{606}$ because of better coverage of protein-coding sequences and higher sensitivity for other types of mutations. ${ }^{10}$ This equates to a potential total diagnosis rate of $\sim 75 \%$ if genomic testing combined with chromosome microarray is used as a firstline testing approach. ${ }^{710}$

Genomic testing can result in a reduction in the time to a clinical diagnosis to under a week, resulting in fewer expensive and invasive diagnostic tests, and faster progression to genespecific genetic counselling. ${ }^{62}$ Genomic testing may also result in patients being referred to a clinical geneticist and/or an appropriate specialist earlier in the diagnostic odyssey, avoiding inefficient use of healthcare resources. The costs of prior negative diagnostic testing in patients who eventually receive a diagnosis through either traditional genetic diagnostic evaluations or genomic testing have been estimated to be between US $\$ 19000^{1}$ and US\$25000. ${ }^{6}$ By contrast, genomic testing can result in savings to the healthcare system that exceed the costs of generating the data and undertaking the analysis for the entire tested cohort. $^{61}$

As novel causes of ID are identified, the number of treatable forms of ID is expected to increase as new therapies are developed. ${ }^{63}$ Although newborn screening is important to ensure optimal lifetime health outcomes for treatable conditions, it is unlikely that, in the short term, many effective treatments linked to genomic testing for ID will be available. ${ }^{64}$ There are, however, many existing management options and therapies for ID, the costs of which are captured in table 1 . Thus, improved diagnosis through genomic testing is unlikely to have a large impact on social expenditures for affected individuals in the short term.

The refinement of recurrence risk through gene identification has important impacts on families and the choices available to them. When the risk is high, it facilitates access to reproductive testing, such as prenatal diagnosis and in vitro fertilisation with preimplantation genetic screening. When the risk is low with the diagnosis of a de novo ID aetiology, reproductive confidence is often restored, the consequences being an increased number of healthy children. Increased reproductive options based on the availability of a specific molecular diagnosis are beginning to affect health and social expenditure, while emerging targeted treatments may also have a significant impact in the future. In the first instance, a corrected appreciation of the overall costs for people living with significant disabilities should allow for more appropriate levels of societal funding to enable improved living standards and appropriate allocation of healthcare and daily living resources.

Genomic testing has expanded into clinical settings and has replaced traditional diagnostic methods primarily early in life for Mendelian disorders. ${ }^{65}$ The benefits of WES and WGS show the highest current utility in monogenic disorders such as ID. As genomic diagnostics replace single-gene testing, not only will savings of US\$19000-\$2500016 that would have been expended on diagnostic odysseys accrue, but also such testing will also provide cumulative benefits throughout life such as preconception carrier screening and pharmacogenomics testing. Genomic diagnostics is, however, unlikely to replace inexpensive screening methodologies such as tandem mass spectrometry in the foreseeable future, with such testing remaining important due to its accuracy, low cost and ability to provide functional data.

This is one of the first studies to review and synthesise the potential economic and social benefits of implementing genomic testing. It also provides one of the most comprehensive syntheses of the healthcare and social costs of intellectual and physical disability as they relate to genetic disorders. This study therefore provides a foundation for more robust economic evaluations of genomic testing in ID.

The majority of studies (62\%) used in our costing analysis of intellectual and physical disability were conducted in the UK, resulting potentially in cost distortions when applied to different countries. To account for this, lower, middle and upper boundary estimates were derived, and a mean value with its associated range was calculated to account for this uncertainty. Due to the limited data available concerning the cost of disability related to genetic conditions, it was considered reasonable to assume that cost estimates from conditions resulting in a similar type and degree of disability were comparable. Only $7^{23} 323346474951$ of the 27 studies used in the cost analysis reported the costs of intellectual and physical disability as the amount excess of routine healthcare and social expenditures (ie, attributable to disability only) (references highlighted in bold in online supplementary tables S2 and S3). Adjusting for population-level health and social expenditures would, however, be unlikely to alter our total cost estimates significantly due to the magnitude of the total health and social costs reported in our study. Finally, despite our costing analysis, including a wide range of healthcare and social costs, some costs were not captured (ie, there were limited data on the costs of aids and modifications), and so the costs presented here still represent an underestimate.

There are advantages of providing access to genomic testing for families with a child with ID as de novo events will be the aetiology in about $50 \%$ of cases: a single genomic investigation can therefore restore reproductive confidence by providing recurrence information and reassurance. The interpretation of individual genomic data will be iterative and its value will increase rapidly as genomic variants are integrated with population clinical information in genotype-phenotype databases. ${ }^{13}$ Such international databases need to be established and maintained to provide privacy-protected genomic and linked medical information for evidence-based care. The availability of genotype-phenotype databases will improve the clinical utility of genomics and assist with targeting healthcare resources. The use of increasingly well-populated genotype-phenotype databases will also dramatically reduce the costs of analysis by correlating variants with clinical features. The availability of lower cost genomic testing combined with a high diagnostic utility and the potential to restore reproductive confidence will result in genomic testing becoming the standard for diagnostic medicine.

This study has produced a comprehensive accumulated dataset of the costs associated with the care of people with ID throughout life, which exceed many millions of dollars per person. The cost of care is many fold higher than that considered in the older literature and highlights the chasm between the support that people with ID and their families require and the low levels of current funding. These updated health and social costs should become the new reference point for the provision of appropriate funding support for people living with disabilities.

Contributors Conceptualisation: BD, DS, JSM and TR; methodology: BD, DS, TG $M F$ and TR; formal analysis and investigation: $B D, C-A E, T G$ and MF; writing (original 
draft preparation): BD; writing (review and editing): DS, C-AE, TG, JSM, MF and TR; supervision: DS, JSM and TR; overall content guarantor: BD.

Funding TR, DS, MF, TG and C-AE were supported through the National Health and Medical Research Council (NHMRC) Centre for Research Excellence in Neurocognitive Disorders (grant ID 1117394)

Competing interests None declared.

Patient consent for publication Not required.

Provenance and peer review Not commissioned; externally peer reviewed.

Data availability statement All data relevant to the study are included in the article or uploaded as supplementary information.

\section{ORCID iD}

Brett Doble http://orcid.org/0000-0002-4948-8831

\section{REFERENCES}

1 Soden SE, Saunders CJ, Willig LK, Farrow EG, Smith LD, Petrikin JE, LePichon J-B, Miller NA, Thiffault I, Dinwiddie DL, Twist G, Noll A, Heese BA, Zellmer L, Atherton AM, Abdelmoity AT, Safina N, Nyp SS, Zuccarelli B, Larson IA, Modrcin A, Herd S, Creed $M, Y e Z$, Yuan X, Brodsky RA, Kingsmore SF. Effectiveness of exome and genome sequencing guided by acuity of illness for diagnosis of neurodevelopmental disorders. Sci Transl Med 2014;6:265ra168.

2 Costa T, Scriver CR, Childs B. The effect of Mendelian disease on human health: a measurement. Am J Med Genet 1985;21:231-42.

3 Yoon PW, Olney RS, Khoury MJ, Sappenfield WM, Chavez GF, Taylor D. Contribution of birth defects and genetic diseases to pediatric hospitalizations. A population-based study. Arch Pediatr Adolesc Med 1997;151:1096-103.

4 Kumar P, Radhakrishnan J, Chowdhary MA, Giampietro PF. Prevalence and patterns of presentation of genetic disorders in a pediatric emergency department. Mayo Clin Proc 2001:76:777-83.

5 Carmichael N, Tsipis J, Windmueller G, Mandel L, Estrella E. "Is it going to hurt?": the impact of the diagnostic odyssey on children and their families. J Genet Couns 2015:24:325-35.

6 Shashi V, McConkie-Rosell A, Rosell B, Schoch K, Vellore K, McDonald M, Jiang Y-H, Xie P, Need A, Goldstein DB, Goldstein DG. The utility of the traditional medical genetics diagnostic evaluation in the context of next-generation sequencing for undiagnosed genetic disorders. Genet Med 2014;16:176-82.

7 Rauch A, Hoyer J, Guth S, Zweier C, Kraus C, Becker C, Zenker M, Hüffmeier U, Thiel $C$, Rüschendorf $F$, Nürnberg $P$, Reis A, Trautmann U. Diagnostic yield of various genetic approaches in patients with unexplained developmental delay or mental retardation. Am J Med Genet A 2006;140:2063-74.

8 Yang Y, Muzny DM, Xia F, Niu Z, Person R, Ding Y, Ward P, Braxton A, Wang M, Buhay C, Veeraraghavan N, Hawes A, Chiang T, Leduc M, Beuten J, Zhang J, He W, Scull J, Willis A, Landsverk M, Craigen WJ, Bekheirnia MR, Stray-Pedersen A, Liu P, Wen S, Alcaraz W, Cui H, Walkiewicz M, Reid J, Bainbridge M, Patel A, Boerwinkle E, Beaudet AL, Lupski JR, Plon SE, Gibbs RA, Eng CM. Molecular findings among patients referred for clinical whole-exome sequencing. JAMA 2014;312:1870-9.

9 Bloss CS, Zeeland AAS-V, Topol SE, Darst BF, Boeldt DL, Erikson GA, Bethel KJ, Bjork RL, Friedman JR, Hwynn N, Patay BA, Pockros PJ, Scott ER, Simon RA, Williams GW, Schork NJ, Topol EJ, Torkamani A. A genome sequencing program for novel undiagnosed diseases. Genet Med 2015;17:995-1001.

10 Mattick JS, Dinger M, Schonrock N, Cowley M. Whole genome sequencing provides better diagnostic yield and future value than whole exome sequencing. Med J Aust 2018:209:197-9.

11 Frank M, Prenzler A, Eils R, Graf von der Schulenburg J-M. Genome sequencing: a systematic review of health economic evidence. Health Econ Rev 2013;3:29.

12 van Nimwegen KJM, Schieving JH, Willemsen MAAP, Veltman JA, van der Burg S, van der Wilt GJ, Grutters JPC. The diagnostic pathway in complex paediatric neurology: a cost analysis. Eur J Paediatr Neurol 2015;19:233-9.

13 Ewans LJ, Schofield D, Shrestha R, Zhu Y, Gayevskiy V, Ying K, Walsh C, Lee E, Kirk EP, Colley A, Ellaway C, Turner A, Mowat D, Worgan L, Freckmann M-L, Lipke M, Sachdev R, Miller D, Field M, Dinger ME, Buckley MF, Cowley MJ, Roscioli T. Whole-Exome sequencing reanalysis at 12 months boosts diagnosis and is cost-effective when applied early in Mendelian disorders. Genet Med 2018;20:1564-74.

14 Monroe GR, Frederix GW, Savelberg SMC, de Vries TI, Duran KJ, van der Smagt JJ, Terhal PA, van Hasselt PM, Kroes HY, Verhoeven-Duif NM, Nijman IJ, Carbo EC, van Gassen KL, Knoers NV, Hövels AM, van Haelst MM, Visser G, van Haaften G. Effectiveness of whole-exome sequencing and costs of the traditional diagnostic trajectory in children with intellectual disability. Genet Med 2016;18:949-56.

15 Vrijenhoek T, Middelburg EM, Monroe GR, van Gassen KLI, Geenen JW, Hövels AM, Knoers NV, van Amstel HKP, Frederix GWJ. Whole-Exome sequencing in intellectual disability; cost before and after a diagnosis. Eur J Hum Genet 2018;26:1566-71.

16 Stark Z, Schofield D, Martyn M, Rynehart L, Shrestha R, Alam K, Lunke S, Tan TY, Gaff $\mathrm{CL}$, White SM. Does genomic sequencing early in the diagnostic trajectory make a difference? A follow-up study of clinical outcomes and cost-effectiveness. Genet Med 2019;21:173-80.
17 Németh AH, Kwasniewska AC, Lise S, Parolin Schnekenberg R, Becker EBE, Bera KD, Shanks ME, Gregory L, Buck D, Zameel Cader M, Talbot K, de Silva R, Fletcher N, Hastings R, Jayawant S, Morrison PJ, Worth P, Taylor M, Tolmie J, O'Regan M, Valentine R, Packham E, Evans J, Seller A, Ragoussis J, UK Ataxia Consortium. Next generation sequencing for molecular diagnosis of neurological disorders using ataxias as a model. Brain 2013:136:3106-18.

18 Valencia CA, Husami A, Holle J, Johnson JA, Qian Y, Mathur A, Wei C, Indugula SR, Zou F, Meng H, Wang L, Li X, Fisher R, Tan T, Hogart Begtrup A, Collins K, Wusik KA, Neilson D, Burrow T, Schorry E, Hopkin R, Keddache M, Harley JB, Kaufman KM, Zhang K, Impact C. Clinical impact and cost-effectiveness of whole exome sequencing as a diagnostic tool: a pediatric center's experience. Front Pediatr 2015;3.

19 Drummond MF, Sculpher MJ, Torrance GW, O'Brien BJ, Stoddart GL. Methods for the economic evaluation of health care programmes. 3rd edn. New York: Oxford University Press Inc, 2005.

20 Schwarze K, Buchanan J, Taylor JC, Wordsworth S. Are whole-exome and wholegenome sequencing approaches cost-effective? A systematic review of the literature. Genet Med 2018;20:1122-30.

21 Alam K, Schofield D. Economic evaluation of genomic sequencing in the paediatric population: a critical review. Eur I Hum Genet 2018;26:1241-7.

22 Online Mendelian Inheritance in Man. OMIM®. 2019 edn. Baltimore, MD: McKusickNathans Institute of Genetic Medicine, Johns Hopkins University, 2019.

23 Knapp M, Romeo R, Beecham J. Economic cost of autism in the UK. Autism 2009:13:317-36

24 Australian Institute of Health and Welfare. Disability support services: services provided under the National disability agreement. Bulletin No. 122. cat. No. AUS 182. Canberra: AlHW, 2014.

25 Organisation for Economic Co-Operation and Development (OECD). Stata - Consumer price indicies (CPIS). 2019 edn. OECD, 2019.

26 Australian Bureau of Statistics. 6345.0 - Wage Price Index. Australia: Commonwealth of Australia, 2019.

27 Clark G. The annual RPI and average earnings for Britain, 1209 to present (new series). 2019 ed. MeasuringWorth, 2019.

28 Officer LH, Williamson SH. Annual wages in the United States unskilled labor and manufacturing workers 1774-Present. 2019 ed. MeasuringWorth, 2019.

29 United Nations Economic Commission for Europe (UNECE). Gross average monthly wages by country and year. $2019 \mathrm{ed}$. UNECE, 2019.

30 Sacco P, Capkun-Niggli G, Zhang X, Jose R. The economic burden of fragile X syndrome: healthcare resource utilization in the United States. Am Health Drug Benefits 2013;6:73-83.

31 Romeo R, Knapp M, Morrison J, Melville C, Allan L, Finlayson J, Cooper S-A. Cost estimation of a health-check intervention for adults with intellectual disabilities in the UK. J Intellect Disabil Res 2009;53:426-39.

32 Buescher AVS, Cidav Z, Knapp M, Mandell DS. Costs of autism spectrum disorders in the United Kingdom and the United States. JAMA Pediatr 2014;168:721-8.

33 Doran CM, Einfeld SL, Madden RH, Otim M, Horstead SK, Ellis LA, Emerson E. How much does intellectual disability really cost? first estimates for Australia. J Intellect Dev Disabil 2012:37:42-9.

34 Emerson E, Robertson J, Gregory N, Kessissoglou S, Hatton C, Hallam A, Knapp M, Järbrink $\mathrm{K}$, Netten $\mathrm{A}$, Linehan $\mathrm{C}$. The quality and costs of community-based residential supports and residential campuses for people with severe and complex disabilities. $J$ Intellect Dev Disabil 2000;25:263-79.

35 Flanders SC, Engelhart L, Pandina GJ, McCracken JT. Direct health care costs for children with pervasive developmental disorders: 1996-2002. Adm Policy Ment Health 2007:34:213-20.

36 Barron DA, Molosankwe I, Romeo R, Hassiotis A. Urban adolescents with intellectual disability and challenging behaviour: costs and characteristics during transition to adult services. Health Soc Care Community 2013;21:283-92.

37 Felce D, Perry J, Romeo R, Robertson J, Meek A, Emerson E, Knapp M. Outcomes and costs of community living: semi-independent living and fully staffed group homes. $A m$ J Ment Retard 2008;113:87-101.

38 Robertson J, Emerson E, Hatton C, Elliott J, McIntosh B, Swift P, Krinjen-Kemp E, Towers C, Romeo R, Knapp M, Sanderson H, Routledge M, Oakes P, Joyce T. Longitudinal analysis of the impact and cost of person-centered planning for people with intellectual disabilities in England. Am J Ment Retard 2006;111:400-16.

39 McGill P, Poynter J. High cost residential placements for adults with intellectual disabilities. J Appl Res Intellect Disabil 2012;25:584-7.

40 Kang T, Harrington C. Variation in types of service use and expenditures for individuals with developmental disabilities. Disabil Health J 2008;1:30-41.

41 Knapp M, Comas-Herrera A, Astin J, Beecham J, Pendaries C. Intellectual disability, challenging behaviour and cost in care accommodation: what are the links? Health Soc Care Community 2005;13:297-306.

42 Felce D, Lowe K, Perry J, Baxter H, Jones E, Hallam A, Beecham J. Service support to people in Wales with severe intellectual disability and the most severe challenging behaviours: processes, outcomes and costs. J Intellect Disabil Res 1998:42:390-408.

43 Stancliffe RJ, Keane $S$. Outcomes and costs of community living: a matched comparison of group homes and semi-independent living. J Intellect Dev Disabil 2000;25:281-305. 
44 Hallam A, Knapp M, Järbrink K, Netten A, Emerson E, Robertson J, Gregory N, Hatton C, Kessissoglou S, Durkan J. Costs of village community, residential campus and dispersed housing provision for people with intellectual disability. J Intellect Disabil Res 2002:46:394-404.

45 Strydom A, Romeo R, Perez-Achiaga N, Livingston G, King M, Knapp M, Hassiotis A Service use and cost of mental disorder in older adults with intellectual disability. $\mathrm{Br} J$ Psychiatry 2010;196:133-8.

46 Noyes J, Godfrey C, Beecham J. Resource use and service costs for ventilatordependent children and young people in the UK. Health Soc Care Community 2006;14:508-22.

47 Kancherla V, Amendah DD, Grosse SD, Yeargin-Allsopp M, Van Naarden Braun K. Medical expenditures attributable to cerebral palsy and intellectual disability among Medicaid-enrolled children. Res Dev Disabil 2012;33:832-40.

48 Revill P, Ryan P, McNamara A, Normand C. A cost and outcomes analysis of alternative models of care for young children with severe disabilities in Ireland. Alter 2013;7:260-74.

49 Beecham J, O'Neill T, Goodman R. Supporting young adults with hemiplegia: services and costs. Health Soc Care Community 2001;9:51-9.

50 Bent N, Tennant A, Swift T, Posnett J, Scuffham P, Chamberlain MA. Team approach versus $A D$ hoc health services for young people with physical disabilities: a retrospective cohort study. Lancet 2002;360:1280-6.

51 Walsh JCP. Cost of disability survey stages 2 and 3 - demonstration of relationship: severity of disability vs cost. Canberra, ACT: Department of Family and Community Services, AGPS, 1999

52 Hughes DPF. A survey of the unavoidable cost of disability among 200 people with quadriplegia. Sydney: The Australian Quadriplegic Association, 1999.

53 Pumkam C, Probst JC, Bennett KJ, Hardin J, Xirasagar S. Health care expenditures among working-age adults with physical disabilities: variations by disability spans. Disabil Health J 2013;6:287-96.

54 Knapp M, Perkins M, Beecham J, Dhanasiri S, Rustin C. Transition pathways for young people with complex disabilities: exploring the economic consequences. Child Care Health Dev 2008;34:512-20.

55 de Ligt J, Willemsen MH, van Bon BWM, Kleefstra T, Yntema HG, Kroes T, Vulto-van Silfhout AT, Koolen DA, de Vries P, Gilissen C, del Rosario M, Hoischen A, Scheffer H, de Vries BBA, Brunner HG, Veltman JA, Vissers LELM. Diagnostic exome sequencing in persons with severe intellectual disability. N Engl J Med 2012;367:1921-9.
56 Medical Services Advisory Committee (MSAC). Public Summary Document: Application No. 1476 - Genetic testing for childhood syndromes. Canberra: MSAC, 2018. http:// www.msac.gov.au/internet/msac/publishing.nsf/Content/1476-public

57 Sboner A, Mu XJ, Greenbaum D, Auerbach RK, Gerstein MB. The real cost of sequencing: higher than you think! Genome Biol 2011;12:125

58 Fokkema IFAC, Taschner PEM, Schaafsma GCP, Celli J, Laros JFJ, den Dunnen JT. LOVD v.2.0: the next generation in gene variant databases. Hum Mutat 2011;32:557-63.

59 Dewey FE, Grove ME, Pan C, Goldstein BA, Bernstein JA, Chaib H, Merker JD, Goldfeder RL, Enns GM, David SP, Pakdaman N, Ormond KE, Caleshu C, Kingham K, Klein TE, Whirl-Carrillo M, Sakamoto K, Wheeler MT, Butte AJ, Ford JM, Boxer L, loannidis JPA, Yeung AC, Altman RB, Assimes TL, Snyder M, Ashley EA, Quertermous T. Clinical interpretation and implications of whole-genome sequencing. JAMA 2014:311:1035-45.

60 Petrikin JE, Cakici JA, Clark MM, Willig LK, Sweeney NM, Farrow EG, Saunders CJ, Thiffault I, Miller NA, Zellmer L, Herd SM, Holmes AM, Batalov S, Veeraraghavan N, Smith LD, Dimmock DP, Leeder JS, Kingsmore SF. The NSIGHT1-randomized controlled trial: rapid whole-genome sequencing for accelerated etiologic diagnosis in critically ill infants. NPJ Genom Med 2018;3.

61 Farnaes L, Hildreth A, Sweeney NM, Clark MM, Chowdhury S, Nahas S, Cakic JA, Benson W, Kaplan RH, Kronick R, Bainbridge MN, Friedman J, Gold JJ, Ding Y, Veeraraghavan N, Dimmock D, Kingsmore SF. Rapid whole-genome sequencing decreases infant morbidity and cost of hospitalization. NPJ Genom Med 2018;3.

62 Saunders CJ, Miller NA, Soden SE, Dinwiddie DL, Noll A, Alnadi NA, Andraws N, Patterson ML, Krivohlavek LA, Fellis J, Humphray S, Saffrey P, Kingsbury Z, Weir JC, Betley J, Grocock RJ, Margulies EH, Farrow EG, Artman M, Safina NP, Petrikin JE, Hall $\mathrm{KP}$, Kingsmore SF. Rapid whole-genome sequencing for genetic disease diagnosis in neonatal intensive care units. Sci Trans/ Med 2012;4:154ra35.

63 Vissers LELM, Gilissen C, Veltman JA. Genetic studies in intellectual disability and related disorders. Nat Rev Genet 2016;17:9-18.

64 Leach EL, Shevell M, Bowden K, Stockler-Ipsiroglu S, van Karnebeek CDM. Treatable inborn errors of metabolism presenting as cerebral palsy mimics: systematic literature review. Orphanet J Rare Dis 2014;9:197.

65 Bodian DL, Klein E, lyer RK, Wong WSW, Kothiyal P, Stauffer D, Huddleston KC, Gaither AD, Remsburg I, Khromykh A, Baker RL, Maxwell GL, Vockley JG, Niederhuber JE, Solomon BD. Utility of whole-genome sequencing for detection of newborn screening disorders in a population cohort of 1,696 neonates. Genet Med 2016;18:221-30. 